\title{
Malignant phyllodes tumors of the breast associating malignancy of both mesenchymal and epithelial components (invasive or in situ ductal carcinoma)
}

\author{
CODRUT-COSMin NiSTOR-CiURBA ${ }^{1,2)}$, OANA ŞOMCUTIAN ${ }^{3)}$, IOAN COSMIN LISENCU ${ }^{1,2)}$, \\ FLORIN LAURENTIU IGNAT ${ }^{1,2)}$, GABRIEL LUCIAN LAZĂR ${ }^{1,2)}$, DAN TUDOR ENIU ${ }^{1,2)}$ \\ 1) Discipline of Surgical and Gynecological Oncology, Department of Oncology, Iuliu Haţieganu University of Medicine and \\ Pharmacy, Cluj-Napoca, Romania \\ 2) Department of Surgical and Gynecological Oncology, Prof. Dr. Ion Chiricuţă Oncological Institute, Cluj-Napoca, Romania \\ ${ }^{3)}$ Department of Pathology, Prof. Dr. Ion Chiricuţă Oncological Institute, Cluj-Napoca, Romania
}

\begin{abstract}
Phyllodes tumors of the breast are biphasic tumors consisting from an epithelial component and a mesenchymal component. Usually, the mesenchymal component of the tumor is the one who dictates the malignancy of the biphasic proliferation. Presence of the malignancy of the both, epithelial [under the form of invasive carcinoma or ductal carcinoma in situ (DCIS)] and mesenchymal components is very rare. Most of the data available from the literature refers to single case presentations. This paper presents the experience of Prof. Dr. lon Chiricută Oncological Institute (IOCN), Cluj-Napoca, Romania, with the malignant phyllodes tumors with both epithelial and mesenchymal components showing malignancy. Over two decades (1999-2018), four cases of malignant phyllodes tumors with concomitant epithelial and mesenchymal malignancy were found and presented as a case series. Two out of four cases were malignant phyllodes tumors harboring invasive breast carcinomas (one case with associated DCIS and one case of pure invasive carcinoma) and two cases were malignant phyllodes tumors with the epithelial component showing DCIS. Average follow-up period was 67 months (from 39 to 132 months) with a disease-free survival of 58 months.
\end{abstract}

Keywords: phyllodes tumor, breast cancer, invasive carcinoma, ductal carcinoma in situ.

\section{Introduction}

Breast phyllodes tumors are rare biphasic (mesenchymal with a typical leaf-like architecture and epithelial) tumors of the breast usually classified in benign, borderline and malignant according to the World Health Organization (WHO) classification of breast tumors [1], on the basis of features like stromal overgrowth, atypia, infiltrative borders, mitosis rate, presence of necrosis [1,2]. Usually is the mesenchymal component the one to dictate the malignancy of the tumor $[1,2]$. Presence of the malignancy of both epithelial [under the form of invasive carcinoma or ductal carcinoma in situ (DCIS)] and mesenchymal components at the same time is an even rarer finding. That is why most of the literature data refers to single case presentations [3-6] or small series presentations [7-10] but also that is why it is a challenging diagnostic for the pathologists $[1,2,11]$. It is believed that malignancy of the epithelial component of phyllodes tumor occurs in less than $1 \%$ of all phyllodes tumors [8].

We could not find any Romanian prior experience with such cases or series.

\section{Aim}

Current paper presents the experience of Prof. Dr. Ion Chiricuţă Oncological Institute (IOCN), Cluj-Napoca, Romania, with the cases of malignant phyllodes tumors of the breast harboring malignancy of both mesenchymal and epithelial components of the tumor.

\section{ㅁ Patients, Materials and Methods}

To obtain data about all the cases of malignant phyllodes tumors, the Digital Database of the Department of Pathology from IOCN was searched for malignant phyllodes tumors, from the beginning (1999) of our digital records to 31.12.2018. A total of 114 distinct cases of malignant phyllodes tumors were found. The search was done for both International Classification of Diseases for Oncology (ICD-O) C50 and ICD-O 9020/3 codes.

All the reports were reviewed and for five cases, we found coexistence of malignant phyllodes tumors and invasive carcinoma or DCIS in the same breast.

The remaining five cases were reviewed; after each case was reviewed by a senior pathologist to re-confirm the diagnosis, according to current $\mathrm{WHO}$ classifications, four cases were reconfirmed. These four cases form the series we present in this article.

All cases have written consent obtained during hospitalization for publishing data (information and photos) from their medical files.

All data presented in this article was obtained from IOCN Institutional Cancer Registry.

Present study has the authorization for publication obtained from the Ethics Committee of IOCN, available at the editor.

\section{口 Results}

We present here four cases of malignant phyllodes

This is an open-access article distributed under the terms of a Creative Commons Attribution-NonCommercial-ShareAlike 4.0 International Public License, which permits unrestricted use, adaptation, distribution and reproduction in any medium, non-commercially, provided the new creations are licensed under identical terms as the original work and the original work is properly cited. 
tumors that showed malignant transformations in both epithelial and mesenchymal structures. The age of the patients ranged from 45 to 75 years and average age at presentation was 60.25 years. Average follow-up was 67 months (39 to 132 months). The main characteristics of the patients in our group are presented in Table 1.

Table 1 - Main descriptive features of the cases

\begin{tabular}{|c|c|c|c|c|}
\hline Feature & $\begin{array}{l}\text { Case } \\
\text { No. } 1\end{array}$ & $\begin{array}{l}\text { Case } \\
\text { No. } 2\end{array}$ & $\begin{array}{l}\text { Case } \\
\text { No. } 3\end{array}$ & $\begin{array}{l}\text { Case } \\
\text { No. } 4\end{array}$ \\
\hline Age [years] & 50 & 71 & 45 & 75 \\
\hline Dimension [cm] & 11 & 5 & 6 & 4 \\
\hline $\begin{array}{c}\text { Grade of } \\
\text { mesenchymal } \\
\text { component }\end{array}$ & 2 & 1 & 1 & 2 \\
\hline $\begin{array}{c}\text { No. of mitoses/ } \\
10 \mathrm{HPFs}\end{array}$ & 25 & 12 & 13 & 20 \\
\hline Differentiation & Chondrosarcoma & 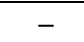 & 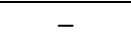 & - \\
\hline $\begin{array}{c}\text { Epithelial } \\
\text { component } \\
\text { malignancy } \\
\end{array}$ & $\begin{array}{l}\text { IDC + } \\
\text { DCIS }\end{array}$ & IDC & DCIS & $\begin{array}{l}\text { IDC + } \\
\text { DCIS }\end{array}$ \\
\hline $\begin{array}{l}\text { Grade of } \\
\text { epithelial } \\
\text { component }\end{array}$ & 3 & 1 & 2 & 2 \\
\hline $\begin{array}{c}\text { Type of } \\
\text { epithelial } \\
\text { component }\end{array}$ & NST & NST & $\begin{array}{c}\text { Solid, } \\
\text { cribiform }\end{array}$ & NST \\
\hline$E R[\%]$ & 0 & 98 & 10 & 0 \\
\hline$P R[\%]$ & 0 & 98 & 10 & 0 \\
\hline Ki67 [\%] & 45 & 10 & - & 35 \\
\hline $\begin{array}{l}\text { Follow-up } \\
\text { [months] }\end{array}$ & 132 & 39 & 41 & 56 \\
\hline DFS [months] & 132 & 39 & 27 & 34 \\
\hline $\begin{array}{c}\text { Death from } \\
\text { tumor [months] }\end{array}$ & - & - & - & 56 \\
\hline
\end{tabular}

HPFs: High-power fields; ER: Estrogen receptor; PR: Progesterone receptor; DFS: Disease-free survival; IDC: Invasive ductal carcinoma; DCIS: Ductal carcinoma in situ; NST: No special type.

For a better understanding of our series, we decided to briefly present every case.

\section{Case No. 1}

Patient, MA, 50-year-old, from a town in Cluj County
(Romania), presented in June 2000 in IOCN with a left breast tumor of $12 / 10 \mathrm{~cm}$.

She had no family history of cancers or other significant illness.

She had no surgical antecedents and no important comorbidities, apart from moderate high blood pressure controlled with medication (Captopril).

The patient discovered the tumor three weeks ahead of the presentation at IOCN by palpation, as a mass in the left breast, of about $7 \mathrm{~cm}$, and she decided to go to her family doctor after two weeks when she found that the tumor was growing rapidly. She was directed to IOCN.

At presentation, patient was in good health, with no important comorbidities, no known allergies, premenopausal. Clinical exam revealed a $12 / 10 \mathrm{~cm}$ tumor of the left breast deforming the whole breast, polylobate, partially well delimited, without skin ulceration but with skin adhesion, mobile on the pectoral plane, without axillary adenopathy. The contralateral breast and axilla and both supraclavicular areas were without pathological changes.

With clinical suspicion of malignant phyllodes tumor, a mammogram was done and revealed a bulky nodular opacity of $10 \mathrm{~cm}$ diameter of the left breast, partial well delimited, with intraductal microcalcifications in the tumor. The mammogram was interpreted as highly suspect of malignancy and a biopsy was requested.

An excisional biopsy was performed, with an intraoperative on ice pathological examination confirming malignancy. In the same surgical session, left modified Madden mastectomy has been carried out. Postoperative evolution was simple with no complication.

Definitive pathological report showed a giant tumor of $11 / 8 \mathrm{~cm}$ with microscopic structure of a malignant phyllodes tumor with chondrosarcomatous differentiation associating areas of intraductal breast carcinoma. The mesenchymal component was G2, with 25 mitoses/10 highpower fields (HPFs), while the epithelial component was $\mathrm{G} 3$, estrogen receptor (ER) and progesterone receptor (PR) negative, with a $45 \% \mathrm{Ki} 67$ factor. No axillary nodes metastasis ( $\mathrm{N} \mathrm{0/22)}$ was found (Figure 1, a and b).

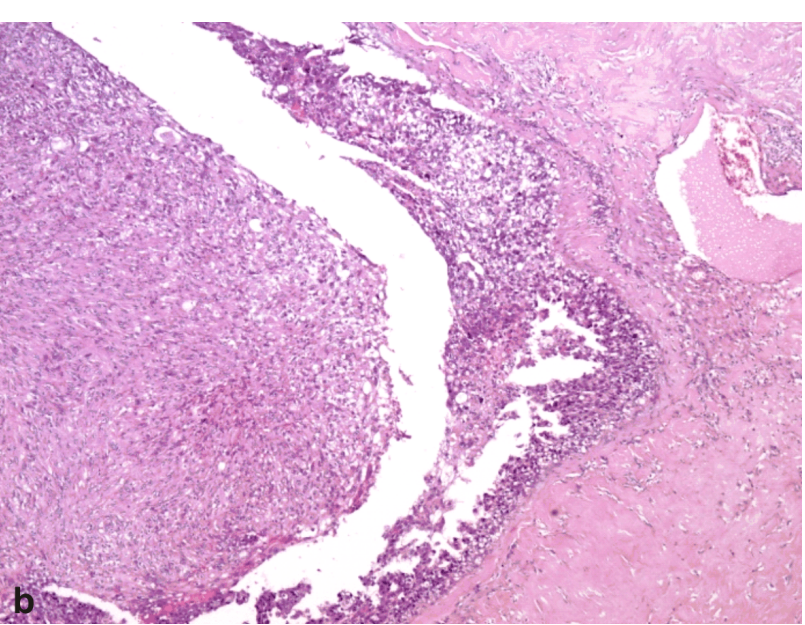

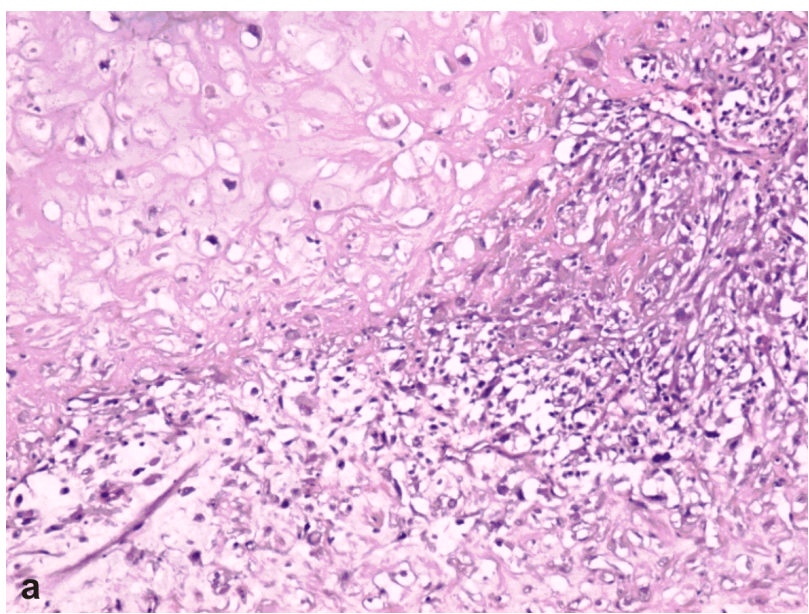

Figure 1 - (a) Chondrosarcomatous differentiation within the malignant mesenchymal component; (b) The malignant mesenchymal component represented by an atypical fusocellular population, located in the immediate vicinity of the epithelial component that has the appearance of DCIS. HE staining: (a) $\times 100$; (b) $\times 40$. DCIS: Ductal carcinoma in situ; HE: Hematoxylin-Eosin.

Computed tomography (CT) scan showed no distant metastasis and Therapeutic Decision Committee recommended adjuvant chemo-radiotherapy, which the patient fulfilled until November 2000. She presented for the followup visits for 11 years (132 months) with no recurrence during the follow-up period and then she was lost from surveillance. 


\section{Case No. 2}

Patient, TA, 71-year-old, from a village of Suceava County (Romania), presented in IOCN in early November 2014 with a right breast tumor of $5 / 5 \mathrm{~cm}$.

The patient had no family history of cancers. Her surgical history included only an appendectomy in the childhood and a laparoscopic cholecystectomy in 2007. She had no oncological antecedents and she had no significant prior illness and no known allergies.

The patient found the tumor two weeks before the presentation in IOCN, by palpation. She presented to her family doctor who directed her in our Service.

At presentation, clinical exam found a $5 / 5 \mathrm{~cm}$ polylobate mass of inhomogeneous consistency, with preserved mobility against the pectoralis plane, with incomplete skin adhesion in the upper and central quadrants (12.00 hours) of the right breast. No axillary or supraclavicular palpable nodes were noted. Left breast and axilla were normal.

Breast ultrasound (US) examination and mammogram have described a $5 / 5 \mathrm{~cm}$ mass, at the junction of the superior quadrants of the right breast (12.00 hours) partially well delimitated, partial seeming invasive, polylobate, inhomogeneous, with calcifications within the tumor, tending to

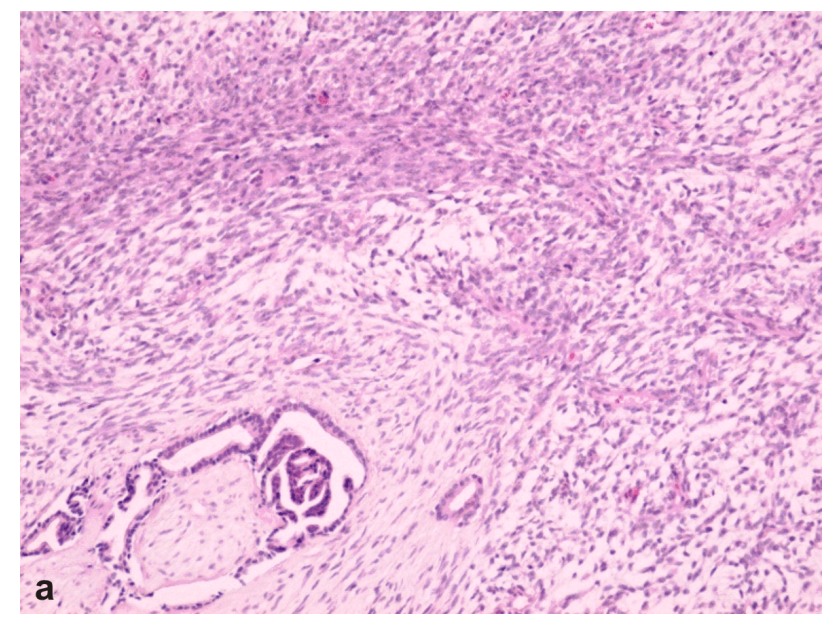

Figure 2 - (a) Mesenchymal-epithelial biphasic aspect: the fusocellular component is predominant and has condensation around the epithelial component; (b) Tubular structures devoid of myoepithelial cells, arranged in a desmoplastic stroma and accompanied by the hypercellular mesenchymal contingent; (c) Microscopic image with epithelial, tubular structures, positive for anti-p63 antibody. $\mathrm{HE}$ staining: (a and b) $\times 100$. Anti-p63 antibody immunostaining: (c) $\times 200$. HE: Hematoxylin-Eosin.

As a result of this pathological report, the patient returned in December 2014, a thorax-abdomen-pelvis CT scan excluded distant metastasis and a modified right radical mastectomy was performed with simple, favorable evolution, the definitive pathological report describing a $5 / 4 \mathrm{~cm}$ tumor with the same features with a posterior extend to the overlying skin. With high suspicion of a malignant phyllodes tumor, the lesion had been classified as Breast Imaging-Reporting and Data System (BI-RADS) 5, demanding biopsy confirmation.

Tru-Cut ${ }^{\circledR}$ biopsy has been done at the time of first presentation and three weeks later, the pathological report showed the presence of a malignant phyllodes tumor associated with a ductal invasive of no special type (NST) carcinoma G1 Nottingham (nuclear grade 1, mitotic grade 1, tube formation 1) without in situ component (Figure 2, $a$ and $b$ ).

The invasive component was described as ER+++ (98\%) and PR+++ (98\%), with human epidermal growth factor receptor 2 (Her2) $1+$ score and a Ki67 index of $<10 \%$, cytokeratin (CK) AE1/AE3 and E-cadherin positive. There was no sign of lymphatic or perineural invasion.

The malignant mesenchymal component of the phyllodes tumor was described by immunohistochemistry (IHC) as smooth muscle actin (SMA) and cluster of differentiation (CD) 10 focally positive, CD34 and p63 positive (Figure 2c); CK AE1/AE3, c-kit, desmin, myoglobin, CK high molecular weight (CKHMW) were negative. It was considered a G1 malignant mesenchymal component with 12 mitoses/ 10 HPFs.
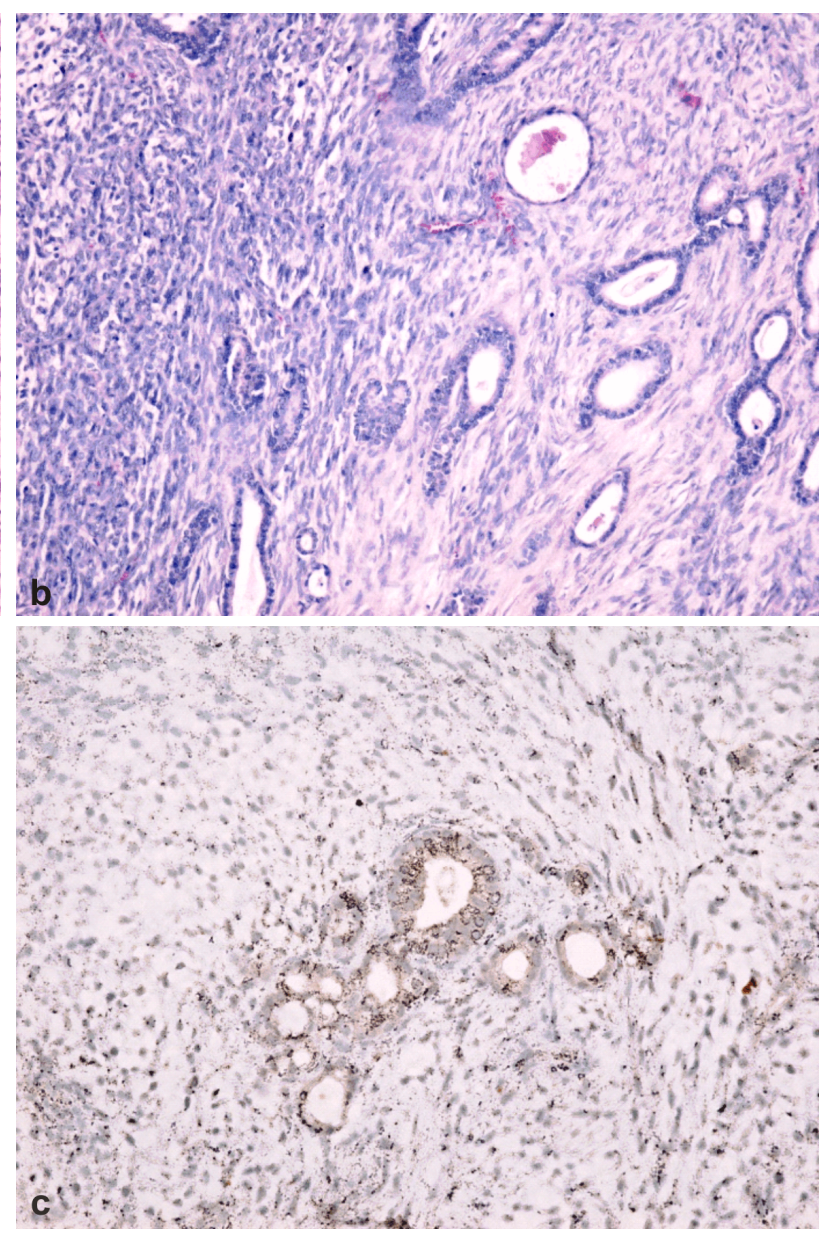

resection margin of less than $1 \mathrm{~mm}$, with 16 negative axillary lymph nodes ( $\mathrm{N} 0 / 16)$.

Therapeutic Decision Committee indicated hormonal therapy and external breast irradiation. The patient underwent the radiotherapy three months after the definitive surgical treatment and presented for the follow-up visits 
39 months after the surgery. During this period of time, she also received hormonal treatment. She was lost from follow-up after 39 months, with no signs of loco-regional or distant recurrence for 39 months after the surgical treatment.

\section{Case No. 3}

Patient, AM, 39-year-old, from a village of Tulcea County (Romania), presented in IOCN Outpatient Service, in June 2010, with a 7/7 cm left breast tumor discovered by the patient (inspection and palpation) two months before the presentation.

The patient had no family history of cancers and also no relatives with serious medical conditions. She was in good health; from her medical history, we can mention only a uterine fibromatosis and polycystic kidney. She had no prior surgical treatments and she was not known with allergies.

Two months before the presentation, she observed a mass deforming her left breast and at palpation, she describes the tumor as about $6 / 6 \mathrm{~cm}$. A few weeks after, she visited her family doctor, who sent her for breast US and mammographic investigations. Both described a $6 / 6 \mathrm{~cm}$ well delimited left breast mass at the junction of the superior quadrants with no skin or pectoral invasion. The tumor was polylobate, inhomogeneous, with a structural mix of fluid and solid parts, with some calcifications in the solid component. It was interpreted as a possible phyllodes tumor and she was referred to IOCN. No other breast tumor was found bilaterally and no axillary adenopathy was found bilateral.

Clinical examination at presentation found a still mobile on the pectoral plane, $7 / 7 \mathrm{~cm}$ mass, inhomogeneous, polylobate, with different consistencies within the tumor (fluid and solid). The tumor was also mobile against the overlaying skin. No other tumor was found in the breasts

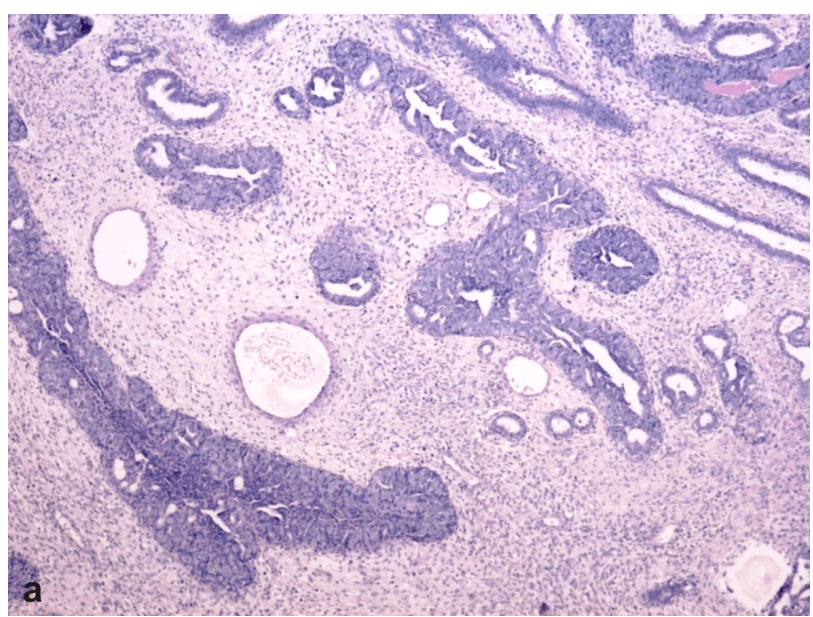

bilaterally and there was no supraclavicular or axillary (bilateral) lymphadenopathy.

With the suspicion of a phyllodes tumor, an excisional biopsy was performed with an intraoperative ice and definitive pathological result of a borderline phyllodes tumor, with maximum five mitoses/10 HPFs. The exuberant epithelial component showed areas of ductal typical hyperplasia.

She refused any further re-excision and come only for one follow-up visit, at three months.

After six years, she presented again in the IOCN Outpatient Service, in September 2016, with a left breast mass of about $10 / 7 \mathrm{~cm}$, involving the central and upper quadrants of the left breast, with no supraclavicular or axillary (bilateral) adenopathy. The tumor was worst delimited than first time, also presented mixed consistency, with alternation of solid and liquid areas, but still was mobile on the pectoral plane. No axillary or supraclavicular (bilateral) adenopathies were noted. Right breast was normal.

The tumor was first noticed by the patient three months before the presentation by palpation as a $5 \mathrm{~cm}$ diameter mass at that time. When she realized that the tumor was growing fast, she presented in IOCN.

The mammogram showed a $10 / 7 \mathrm{~cm}$ left breast mass, partial well delimited, partial invasive, inhomogeneous, with mixed structure (fluid and solid) with microcalcifications within the tumor.

An excision was performed (patient refused core biopsy). Pathological report stated malignant phyllodes tumor, with 12-13 mitoses/10 HPFs in the most active areas of the malignant mesenchymal component, with invasion front, necrosis and infarction on about $25 \%$ of the section surface, with the typical leaf-like feature. No differentiation of the mesenchymal component was noted. As for the mesenchymal component, a G2 malignancy was assigned (Figure 3, a and b).

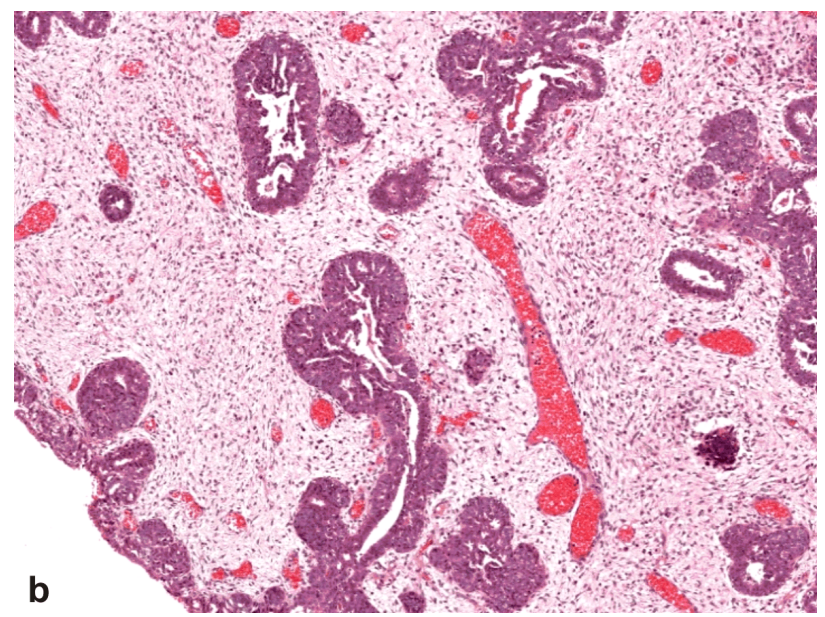

Figure 3 - (a) Epithelial contingent represented by ductal structures with DCIS lesions with cribriform and solid architecture; (b) DCIS lesions with micropapillary architecture, surrounded by a hypercellular mesenchymal contingent, composed of fusiform cells, with mild, mitotically-active atypia. HE staining: (a) $\times 40$; (b) $\times 100$. DCIS: Ductal carcinoma in situ; HE: Hematoxylin-Eosin.

Within the tumor foci, solid, moderate grade (G2) DCIS were found in the epithelial component. Those were ER+ $(10 \%)$ and $\mathrm{PR}+(10 \%), \mathrm{p} 63$ positive and CK5 negative.

For our study, we considered this moment, of the first diagnosis of malignant phyllodes tumor associated with DCIS, as the T0 moment for the follow-up.
The patient was recalled for further treatment (mastectomy/irradiation) but she refused and she did not came for follow-up visits until January 2019 when, after 27 months, she presented with a big $9 / 8 \mathrm{~cm}$ tumor in the same left breast, entirely deforming the upper and central quadrants of the breast. From the anamneses, we found 
out that the tumor reappeared 3-4 months before the presentation. The tumor had the same clinical features, inhomogeneous, polylobate, mobile on the pectoralis plane but tending to be invaded by the overlying skin and the surrounding fat tissue. No left axillary or supraclavicular adenopathy were found. Right breast, axilla and supraclavicular area were normal.

Bilateral mammogram showed a bulky 90/80 mm left breast opacity partially well delimited, partially irregular, tending to invade the surrounding tissues, with round calcifications within the tumor. No lymphadenopathies were noted.

CT scan was normal, with no distant metastasis.

A left mastectomy with sentinel node biopsy was performed in January 2019, with simple favorable evolution. The pathological report stated a $6 / 6 \mathrm{~cm}$ bulky, polylobate, friable tumor, with a minimum $1 \mathrm{~cm}$ resection margin (posterior) of sane tissue.

The fibroepithelial proliferation had a mitotic index of 10-11 mitoses/10 HPFs and showed leaf-like features, invasion front, necrosis (approximately $25 \%$ of the section surface), foci of DCIS solid and cribriform, moderate nuclear grade $(\mathrm{G} 2)$ inside the tumor but this time also in the vicinity of the tumor. Sentinel lymph node biopsy showed no sign of malignity in the Hematoxylin-Eosin (HE) and IHC staining (for CK AE1/AE3).

Given the result, no further treatment was recommended and the patient, this time, presented for the follow-up visits, with no signs of distant or loco-regional recurrences.

\section{Case No. 4}

Patient, TS, 75-year-old, from a small town in Cluj County (Romania), presented in IOCN Outpatient Service, in July 2014, with a left breast, $4 / 3 \mathrm{~cm}$, mass.

The patient discovered the mass a few weeks ago by palpation, she presented to her family doctor who directed her to IOCN Outpatient Service.

From her medical history is to be retained a Parkinson's disease, stage IIIC (very high-risk) hypertension under

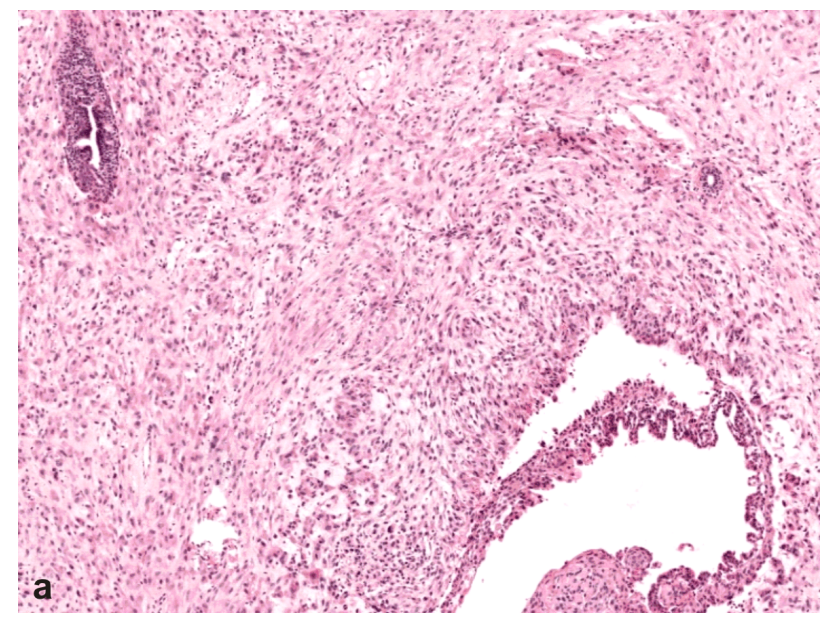

treatment and atrial fibrillation (under treatment). In addition, she had multiple allergies. She had no relatives with cancer history.

Clinical examination found a $4 / 3 \mathrm{~cm}$ mass in the left breast, partially well delimited, partial imprecise delimited, invasive in the surrounding tissues, mobile on the thoracic wall, not invading the pectoralis plane, with partial adhesion to the overlying skin, situated in the superior-external quadrant of the left breast. Also, a $1.5 \mathrm{~cm}$ high consistency, mobile, left axillary adenopathy was noted. No supraclavicular (bilateral) adenopathy was found. Right breast and axilla were normal.

A mammogram and a breast US examination were performed, showing a BI-RADS 5, 4/3 cm left breast tumor in the outer-external quadrant, partially well delimited, partially imprecise delimited, inhomogeneous, polylobate, seeming to invade the surrounding tissues in some parts. Microcalcifications were present inside the tumor, especially in a $2 / 1.5 \mathrm{~cm}$ area, which seemed to be more speculate, solid and invasive. Also, the left adenopathy was described.

CT scan showed no distant metastasis.

A core biopsy was performed with pathological result of phyllodes tumor, with not much information due to the relative small specimens and recommendation for excisional biopsy, which was performed in August 2014 with intraoperative, at ice, pathological exam showing malignancy (malignant phyllodes tumor associated with carcinoma). A left radical modified Madden mastectomy was performed in the same operative session, with simple, favorable evolution.

The pathological report revealed a $4 / 3 \mathrm{~cm}$ tumor consisting from a malignant phyllodes tumor associated with invasive breast carcinoma NST $(2 / 1.7 \mathrm{~cm}$ epithelial component) Nottingham II (histological grade 2, nuclear grade 2, mitotic grade 1) and moderate grade (G2) solid DCIS associated on approximately $5 \%$ of the sections (Figure 4, $a$ and $b$ ).

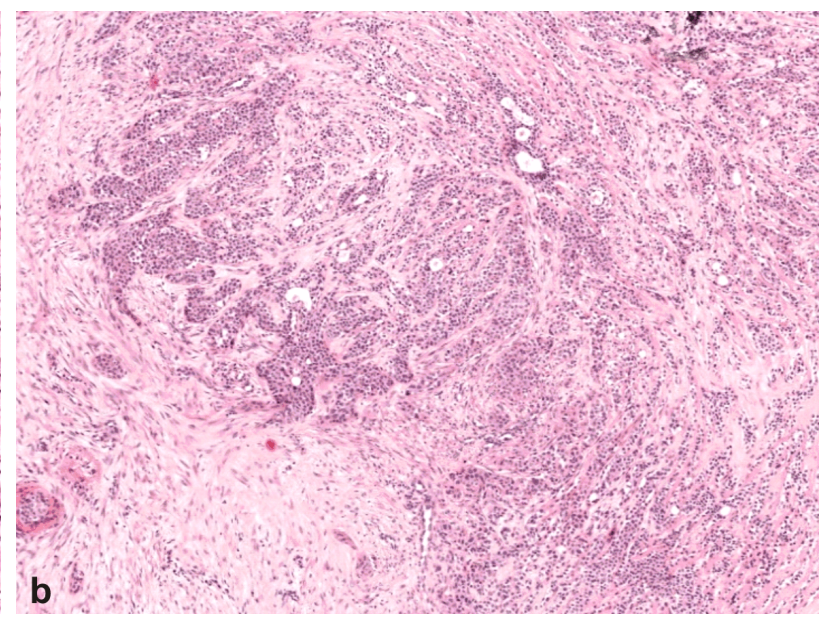

Figure 4 - (a) Typical biphasic aspect with the predominance of the mesenchymal, hypercellular contingent, with nuclear atypia and mitotic activity; (b) Image of malignant epithelial component represented by a proliferation of epithelial cells with moderate atypia, arranged in trabeculae and focally drawing glandular lumens. HE staining: (a) $\times 100$; (b) $\times 40$.

Within the tumor, necrosis was focal; no angiolymphatic or perineural invasion was noted.

The epithelial component was a triple negative (ER $0 \%$,

PR 0\%, Her2 - 0) breast cancer, with a Ki67 proliferation index of $35 \%$.

The malignant mesenchymal component had the 
following IHC features: SMA, CD10, CKHMW, CK AE1/AE3, p63 and CK5/6 focal positive, CD34 and ckit negative. Mitotic index was 20 mitoses/10 HPFs in the most active parts of the mesenchymal component.

No axillary metastasis was found among the 24 axillary lymph nodes examined ( $\mathrm{N} 0 / 24)$.

Therapeutic Decision Committee indicated external radiotherapy, which was delivered in November 2014. The patient presented for follow-up since May 2017 when a 4/3.5 cm was found in the right breast associated with a $2 \mathrm{~cm}$ right axillary adenopathy. Until that time, no locoregional or distant relapse was found. A two-dimensional (2D) + three-dimensional (3D) mammogram was performed showing a highly suggestive for malignancy (BI-RADS 5) right breast mass and a image-guided core biopsy has been performed, confirming the malignancy of the lesion as invasive ductal carcinoma of the breast NST G3 with ER 40\%, PR 40\%, Ki67 index 30\%, Her2 - 0 .

Due to the existing, accentuated cardiac co-morbidity (left ventricle G3 failure, atrial fibrillation with high transmission rate, which could not be converted, stage 3 hypertension), the patient refused surgery, chemotherapy was not possible and hormonal treatment (Anastrozole) has begun. CT scan and whole body scintigraphy at that time revealed no distant metastasis. Under hormone treatment, the cancer progressed rapidly and in three months, the appearance was of inflammatory carcinoma. Although palliative irradiation of the right breast and axilla was delivered and hormonal treatment changed for Exemestane, the evolution was unstoppable, in April 2019 the patient was diagnosed with metastatic bilateral pleurisy, multiple lung and bone (spine and rips) metastasis and died in May 2019, 56 months after the initial treatment.

\section{ㅁ Discussions}

Although phyllodes tumors mainly affect women in their 40's [12,13], in our series, the association of malignancy of both components of a phyllodes tumor seems to arise slightly later; only one of the cases was 45 -year-old at the moment of diagnostic; average age was 60.25 years, with two cases over 70 years ( 71 and 75 years old, respectively). This is in accordance with data published by some authors $[7,8]$.

To date, only a few studies in literature published data about malignant phyllodes tumor of the breast associating malignancy of both mesenchymal and epithelial components. A simple search of PubMed ${ }^{\mathbb{R}}$ returns 1126 items for "malignant phyllodes tumor of the breast" but only 35 items when searching for "malignant phyllodes tumor of the breast associated with breast carcinoma". Some of them are larger studies on phyllodes tumors of all types (benign, borderline and malignant - from the mesenchymal component appearance) and report cases of malignant phyllodes tumors from Singapore [9] presented six cases of malignant epithelial components through phyllodes tumors and the last malignancy of both phyllodes components [7, 9, 14].

A study from British Columbia, Canada [7], presented three cases and another one, from China (South China and Hong Kong) [14], presented six cases of malignant epithelial component of phyllodes tumors, three of them also associating malignancy of the mesenchymal component in the same breast.
Canadian study [7] presented a higher incidence of malignancy of epithelial component among phyllodes tumors $(6 \%)$ compared to other studies $(1 \%)[8,9,14]$. Our series is between the two limits (four cases out of 114 , meaning $3.508 \%$ ).

There is no current proven data about certain types of stromal malignant differentiations to be more often associated with the coexistence of the malignancy of the epithelial component in a malignant phyllodes tumor, although the chondrosarcomatous differentiation is the most common type of mesenchymal differentiation found in malignant phyllodes tumors $[1,2,11,12]$. In our series, also, the only type of differentiation found was the chondrosarcomatous differentiation, present in one case.

Current data in the literature stated that surgical treatment is the main treatment for the malignant phyllodes tumors of the breast. It may be either local excision, with $>10 \mathrm{~mm}$ clear margins or mastectomy $[12,14-18]$. For the tumors with malignancy only of the mesenchymal component, the axillary lymph nodes dissection is not indicated $[12,15-18]$. Due to the association of malignancy of the epithelial component, verifying the axillary status either by sentinel lymph nodes biopsy or axillary lymph nodes dissection is mandatory.

In our series, both cases with invasive breast carcinoma benefited from homolateral axillary lymphadenectomy, both with negative nodes ( $\mathrm{N} \mathrm{0/16,} \mathrm{N} \mathrm{0/24)}$ and one of the cases with DCIS benefited of sentinel node biopsy meanwhile the other had axillary lymphadenectomy (N 0/22).

Both cases with the malignant epithelial component consisting in invasive breast carcinoma were treated by radical modified mastectomy; also, one of the cases in which the epithelial component was DCIS was primary treated by mastectomy. Also, the second case with DCIS was recalled for further treatment but the patient did not show.

If clear margins of $10 \mathrm{~mm}$ or more cannot be achieved, adjuvant radiotherapy is to be delivered [12, 15-19]. Also, association of the malignancy of the epithelial component indicates the radiotherapy in cases of conservative surgical treatment or in case of axillary lymph nodes involvement.

In our study, three of the cases benefited from radiotherapy due to close margins $(<10 \mathrm{~mm})$ even after mastectomy.

The use of chemotherapy in malignant phyllodes tumors is usually reserved for the metastatic cases [16, $18,20]$, but association of the malignancy of the epithelial component may render adjuvant chemotherapy necessary after surgical treatment as an appropriate indication for the malignancy of the epithelial component.

Depending of the ER and PR status, hormonal treatment may be mandatory for the carcinomatous component of the tumor and, also, depending of the Her2 status, specific anti Her2 treatment may be required. In our study, both ER- and PR positive cases were assigned for hormonal therapy. No case was Her2+, so no anti-Her2 treatment has been given.

Although some authors indicate that carcinomas arising from the epithelial component of a malignant phyllodes tumor will behave less aggressive [21], in our study the epithelial component was present in both recurrences (one local recurrence and the other distant metastasis). 
Unfortunately, occurrence of metastasis usually signals imminence of death $[12,13,22]$, with a median of seven months of survival after metastasis appearance. The only case in our series with distant metastasis had a five months survival after metastasis diagnostic.

\section{Conclusions}

Current paper presents the experience of a tertiary health care institution in the management of malignant phyllodes tumors associating the malignancy of both mesenchymal and epithelial components in the form of a four cases series. Apart from the rarity of these tumors, real challenges arise for the whole team involved in the management of such cases, from diagnostic to treatment due to concomitant association of two different malignancies in the same tumor. Of course, the small number of cases is the weak point of present study but given the rarity of these tumors, this might one of the biggest series published to date.

\section{Conflicts of interests}

All authors have no conflicts of interest to declare.

\section{References}

[1] Lakhani SR, Ellis IO, Schnitt SJ, Tan PH, van de Vijver MJ (eds). World Health Organization (WHO) Classification of tumours of the breast. $4^{\text {th }}$ edition, vol. 4, WHO Classification of Tumours, International Agency for Research on Cancer (IARC) Press, Lyon, France, 2012, 143-147.

[2] Tavassoli FA, Devilee P (eds). Pathology and genetics of tumours of the breast and female genital organs. WHO Classification of Tumours, IARC Press, Lyon, France, 2003, 99-103.

[3] Lester J, Stout AP. Cystosarcoma phyllodes. Cancer, 1954 7(2):335-353. https://doi.org/10.1002/1097-0142(195403)7:2 $<335$ ::aid-cncr2820070219>3.0.co;2-j PMID: 13141227

[4] Kodama T, Kameyama K, Mukai M, Sugiura H, Ikeda T, Okada Y. Invasive lobular carcinoma arising in phyllodes tumor of the breast. Virchows Arch, 2003, 442(6):614-616. https://doi.org/10.1007/s00428-003-0826-y PMID: 12743817

[5] Macher-Goeppinger S, Marme F, Goeppert B, Penzel R, Schirmacher P, Sinn HP, Aulmann S. Invasive ductal breast cancer within a malignant phyllodes tumor: case report and assessment of clonality. Hum Pathol, 2010, 41(2):293-296. https://doi.org/10.1016/j.humpath.2009.08.006 PMID: 19896695

[6] Sugie T, Takeuchi E, Kunishima F, Yotsumoto F, Kono $Y$. A case of ductal carcinoma with squamous differentiation in malignant phyllodes tumor. Breast Cancer, 2007, 14(3):327332. https://doi.org/10.2325/jbcs.14.327 PMID: 17690514

[7] Widya RL, Rodrigues MF, Truong PT, Watson PH, Weir LM, Knowling MA, Wai ES. Malignant epithelial transformation in phyllodes tumor: a population-based case series. Cureus, 2017, 9(11):e1815. https://doi.org/10.7759/cureus.1815 PMID: 29312836 PMCID: PMC5752221

[8] Tan PH, Jayabaskar T, Chuah KL, Lee HY, Tan Y, Hilmy M, Hung $\mathrm{H}$, Selvarajan $\mathrm{S}$, Bay $\mathrm{BH}$. Phyllodes tumors of the breast: the role of pathologic parameters. Am J Clin Pathol, 2005, 123(4):529-540. https://doi.org/10.1309/U6DV-BFM8 -1MLJ-C1FN PMID: 15743740

[9] Sin EIL, Wong CY, Yong WS, Ong KW, Madhukumar P, Tan VKM, Thike AA, Tan PH, Tan BKT. Breast carcinoma and phyllodes tumour: a case series. J Clin Pathol, 2016,
69(4):364-369. https://doi.org/10.1136/jclinpath-2015-203475 PMID: 26670744

[10] Sun L, Zhu R, Ginter P, Malik M, Sung KJ, Hughes JM, Siegel B, Tsai J. Coexisting DCIS and phyllodes breast tumors in young Chinese women: case series. Int J Surg Case Rep, 2019, 56:13-16. https://doi.org/10.1016/j.ijscr.2019.01.045 PMID: 30798095 PMCID: PMC6389554

[11] Tan BY, Acs G, Apple SK, Badve S, Bleiweiss IJ, Brogi E, Calvo JP, Dabbs DJ, Ellis IO, Eusebi V, Farshid G, Fox SB, Ichihara S, Lakhani SR, Rakha EA, Reis-Filho JS, Richardson AL, Sahin A, Schmitt FC, Schnitt SJ, Siziopikou KP, Soares FA, Tse GM, Vincent-Salomon A, Tan PH. Phyllodes tumours of the breast: a consensus review. Histopathology, 2016, 68(1): 5-21. https://doi.org/10.1111/his.12876 PMID: 26768026 PMCID: PMC5027876

[12] Mituś J, Reinfuss M, Mituś JW, Jakubowicz J, Blecharz $P$ Wysocki WM, Skotnicki P. Malignant phyllodes tumor of the breast: treatment and prognosis. Breast J, 2014, 20(6):639644. https://doi.org/10.1111/tbj.12333 PMID: 25227987

[13] Mituś JW, Blecharz P, Reinfuss M, Kulpa JK, Skotnicki $P$, Wysocki WM. Changes in the clinical characteristics, treatment options, and therapy outcomes in patients with phyllodes tumor of the breast during 55 years of experience. Med Sci Monit, 2013, 19:1183-1187. https://doi.org/10.12659/MSM. 889687 PMID: 24356679 PMCID: PMC3871490

[14] Co M, Tse GM, Chen C, Wei J, Kwong A. Coexistence of ductal carcinoma within mammary phyllodes tumor: a review of 557 cases from a 20-year region-wide database in Hong Kong and Southern China. Clin Breast Cancer, 2018, 18(3): e421-e425. https://doi.org/10.1016/j.clbc.2017.06.001 PMID: 28689011

[15] Onkendi EO, Jimenez RE, Spears GM, Harmsen WS, Ballman KV, Hieken TJ. Surgical treatment of borderline and malignant phyllodes tumors: the effect of the extent of resection and tumor characteristics on patient outcome. Ann Surg Oncol, 2014, 21(10):3304-3309. https://doi.org/10. 1245/s10434-014-3909-x PMID: 25034817

[16] Adesoye T, Neuman HB, Wilke LG, Schumacher JR, Steiman J, Greenberg CC. Current trends in the management of phyllodes tumors of the breast. Ann Surg Oncol, 2016, 23(10):3199_ 3205. https://doi.org/10.1245/s10434-016-5314-0 PMID: 27334214 PMCID: PMC5021443

[17] Guillot E, Couturaud B, Reyal F, Curnier A, Ravinet J, Laé M, Bollet M, Pierga JY, Salmon R, Fitoussi A; Breast Cancer Study Group of the Institut Curie. Management of phyllodes breast tumors. Breast J, 2011, 17(2):129-137. https://doi.org/ 10.1111/j.1524-4741.2010.01045.x PMID: 21251125

[18] National Comprehensive Cancer Network. Phyllodes tumor (version 3.2019). Accessed: November 19, 2019, https:// www.nccn.org/professionals/physician_gls/pdf/breast.pdf.

[19] Zeng S, Zhang X, Yang D, Wang $\bar{X}$, Ren G. Effects of adjuvant radiotherapy on borderline and malignant phyllodes tumors: a systematic review and meta-analysis. Mol Clin Oncol, 2015, 3(3):663-671. https://doi.org/10.3892/mco.2015.503 PMID: 26137284 PMCID: PMC4471537

[20] Yamamoto S, Yamagishi S, Kohno T, Tajiri R, Gondo T, Yoshimoto N, Kusano N. Effective treatment of a malignant breast phyllodes tumor with doxorubicin-ifosfamide therapy. Case Rep Oncol Med, 2019, 2019:2759650. https://doi.org/ 10.1155/2019/2759650 PMID: 31316848 PMCID: PMC 6604495

[21] Shin YD, Lee SK, Kim KS, Park MJ, Kim JH, Yim HS, Choi YJ. Collision tumor with inflammatory breast carcinoma and malignant phyllodes tumor: a case report and literature review. World J Surg Oncol, 2014, 12:5. https://doi.org/10.1186/ 1477-7819-12-5 PMID: 24400686 PMCID: PMC3895737

[22] Lin CC, Chang HW, Lin CY, Chiu CF, Yeh SP. The clinical features and prognosis of phyllodes tumors: a single institution experience in Taiwan. Int J Clin Oncol, 2013, 18(4):614-620. https://doi.org/10.1007/s10147-012-0442-4 PMID: 22773245

\section{Corresponding author}

Ioan Cosmin Lisencu, MD, PhD, Department of Surgical and Gynecological Oncology, Prof. Dr. Ion Chiricuţă Oncological Institute, 34-36 Republicii Street, 400015 Cluj-Napoca, Romania; Phone +40264-598 361, e-mail: cosminlisencu@yahoo.com 